\title{
Learning from experience
}

\author{
Nigel J Cooke
}

I remember two of the three therapeutic bronchoscopies: forcibly held down by both legs and arms on a hard table with my neck fully extended and my tongue sometimes trapped between unyielding metal and tooth. It seemed an endless torture to remove piecemeal the inspissated pus, blood clot, and sloughed tracheal and bronchial mucosa by repeated removal and reinsertion of both the rigid bronchoscope and forceps. I recall even now the immense relief of unobstructed breathing before continuing hypoxia and toxaemia brought loss of awareness. Long spouted kettles boiled continuously day and night in the steam tent. I burnt my arm on one. Unpleasant sensations of suction through the tracheostomy caused arousal and brought brief glimpses of white figures. My legs were peppered by numerous intramuscular injections. Moments of awareness revealed a nurse in the room or a worried parent. "Eat something, drink something." A subcortical demand for strawberries in October in Birmingham in 1957 was not an easy order to fulfil but they lay uneaten as unconsciousness resumed.

The rigid bronchoscopies were life saving. The first carried out on my "death bed" in the school sanatorium brings no recollection. I have no reason to doubt that the undergraduate friendship from medical school days in Leeds of a general practitioner father and a thoracic surgeon from Oxford summoned in desperation by telephone in the middle of the night was responsible for it being performed at all. I was transferred that day to the nearest thoracic surgical centre at the Queen Elizabeth Hospital in Birmingham. I was 15 years old.
Controversy followed in the correspondence columns of the Lancet. Proponents of bronchoscopy in this clinical setting were labelled as "enthusiastic operators," and opponents claimed that the initial bronchoscopy worsened the inflamed state of the walls of the large airways resulting in the necessity for repeat procedures.

Increasing awareness brought a severe persistent cough to dominate the day and night. There was endless exhausting postural drainage and tracheal suction. I could hit the wall at the end of the bed with some of the more solid lumps of blood and pus that left the tracheostomy tube at great velocity. I can recall the chest radiographs held up to the window on ward rounds showing confluent areas of whiteness. One area was to be watched carefully and fluid to be aspirated from the pleural space on the other. I coughed and coughed but learnt to speak with the tracheostomy tube in place.

My body became emaciated, my posture was appalling, but my appetite returned. I started to notice and remember the faces and bodies of those devoted nurses and physiotherapists and the general relief all around. Medical students expressed their ignorance of the method of closure of a tracheostomy when questioned during a ward teaching. On the way home my father told me that I had nearly died; I think he was right to tell me. I missed a term of school and had to work hard to catch up on the complexities of the efferent and afferent brachial arteries of the dogfish. I survived Asian influenza and secondary bacterial pneumonia when others, young and old, succumbed in thousands.

Chronic cough and sputum production continued for many months. A visit to the
Radcliffe Infirmary in Oxford could only have been to assess whether bronchograms were needed. Knowing now the fate of many patients subjected to surgery in the 1950 s and 1960s for bronchiectasis, I am much relieved that bronchograms were not performed but postural drainage encouraged. As time passed the symptoms slowly subsided.

Thirty years on I have an occasional chest infection and can recommend from personal experience the use of erythromycin when an upper respiratory tract infection threatens, to prevent it "going to my chest." I have normal spirometry and lung volumes, transfer factor, closing volume, chest radiograph, arterial blood gas tensions, and ventilatory responses to hypoxia and hypercapnoea. As a normal subject I have exercised to exhaustion on a treadmill breathing $14 \%$ oxygen with lines in all orifices and blood vessels. My life is insured at normal rates. The story behind my tracheostomy scar has sometimes brought a measure of reassurance to patients and worried relatives.

I do not think that my experience consciously directed my career either into medicine or my specialty. When the next pandemic of influenza strikes, I will be an enthusiastic operator and wield the rigid bronchoscope. If that day comes proponents of learning only fibreoptic bronchoscopy may find themselves inadequately prepared to cope with the cause of subacute large airways obstruction in influenzal necrotising tracheobronchitis. I am grateful for my training in Edinburgh in both techniques.

Nigel 7 Cooke is a general and respiratory physician from Leeds

\section{ANY QUESTIONS}

Is methadone of value in managing chronic dull pain of secondary carcinoma, and has any drug been found to be of value in controlling methadone associated nausea?

Morphine is the strong opioid of choice for cancer pain, with methadone as second choice.' Several centres use methadone as the strong analgesic of choice. It is a totally synthetic opioid of the diphenylpropylamine class, and its pharmacology is broadly similar to that of morphine with $\mu$ receptor specific effects. It is absorbed well from all routes, being half as potent orally as by subcutaneous or intramuscular injection, and there is no obvious ceiling effect. The much longer plasma half life is reflected in a longer duration of action and a tendency to accumulation with repeated dosage, especially in the elderly. Its slower onset and offset of action make it less liable to abuse.

Methadone is slightly more potent than morphine in a single dose, but when used repeatedly it is considerably more potent due to accumulation. In chronic usage its half life increases from 15 hours to two to three days, with a steady state achieved at two to three weeks. Greater care is required in initial stabilisation. Its use should be avoided in the elderly, those who are demented, or those with confusional symptoms. It should also be avoided in people with raised intracranial pressure or in respiratory, hepatic, or renal failure. ${ }^{2}$ Maximum analgesia occurs at one to two hours, which does not correlate with the peak plasma concentrations at four to six hours. The starting dose is $5-10 \mathrm{mg}$ six hourly for three days, reducing to 8-12 mg hourly or at even longer intervals.

Doses of established opioids with similar analgesic effects have a comparative prevalence of side effects, with the same tendency to produce a feeling of wellbeing together with a propensity for nausea and dizziness.

Methadone associated nausea results from its stimulation of the chemoreceptor trigger zone. This can normally be controlled by prochlorperazine 5-10 mg eight hourly, increasing to four hourly if necessary. Haloperidol 1-2 mg daily is a useful alternative. Intramuscular administration for up to two days should control vomiting but if the patient is not nauseated a four day supply of antiemetic should be provided to use prophylactically or as required.' If gastric stasis is a concurrent problem metoclopramide or domperidone may be useful. ${ }^{3}-\mathrm{T}$ P NASH, consultant anaesthetist, Basingstoke

1 World Health Organisation. Cancer pain relief. Geneva: WHO, 1986.

2 Twycross RG. Narcotics. In: Wall PD, Melzack R, eds. Textbook of pain. Harlow, Essex: Churchill Livingstone, 1984:514-25.

3 Regnard C. Nausea and vomiting - a flow diagram. Palliative Medicine 1987;1:62-3. 